\title{
MODELING AND CONTROL OF AN AUTOREFRIGERATED CSTR POLYMERIZATION REACTOR: IMPACT OF THE NON-CONDENSABLE GASES
}

\author{
E. C. Vasco de Toledoa, \\ and R. Maciel Filho ${ }^{a}$,

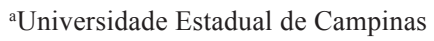 \\ Faculdade de Engenharia Química \\ Cidade Universitária \\ Bairro Barão Geraldo \\ CP 6066 - CEP 13081-970, \\ Campinas, São Paulo, \\ Brasil \\ urso@lopca.feq.unicamp.br

\begin{abstract}
The concept of process intensification is applied to a CSTR polymerization reactor, where bulk reactions take place via styrene free-radicals, connected to a semi-flooded horizontal condenser; the aim is to operate the system in a safe and efficient way. The results obtained show that the developed model was able to reproduce the major dynamic characteristics, even with the presence of non-condensable gases. The existence of such gases prevents the reactor from ever reaching a steady-state, as they accumulate in the system, increasing the condenser pressure and the reactor temperature and reducing the contact area and the mass of liquid in the condenser. To overcome this problem, the control strategy of this work proposes a regular purge of the condenser gases in order to avoid a collapse of the system. In this context, different control algorithms were also analyzed and it was concluded that a fast and reliable control of the reactor is only possible when advanced controllers are used.
\end{abstract} \\ Keywords: process intensification, polymerization reactor, autorefrigerated reactor, model \\ predictive control.
}

\section{NOMENCLATURE}

Ac heat exchange area, $\mathrm{m}^{2}$

$\mathrm{C}_{\mathrm{p}} \quad$ heat capacity, $\mathrm{j} / \mathrm{kg} . \mathrm{K}$

Cte

$\operatorname{CteA}_{c} \mathrm{M}_{L}$

F

I

K

$\mathrm{m}_{\mathrm{nc}}$

$\mathrm{M}$

ML

$\mathrm{P}$

$\mathrm{P}_{\mathrm{c}}$

perc

$\mathrm{T}$

$\mathrm{T}_{1 \mathrm{c}}$

$\mathrm{T}_{\mathrm{a}}$

$\mathrm{U}_{\mathrm{c}}$

V

$\mathrm{W}_{\mathrm{v}}$ proportionality constant of the condenser level control valve, $\mathrm{m}^{3} / \mathrm{kg}$. $\mathrm{s}$ constant relating the heat exchange area and the mass of condensed monomer, $\mathrm{m}^{2} / \mathrm{kg}$

volumetric rate, $\mathrm{m}^{3} / \mathrm{s}$

initiator concentration, $\mathrm{kmol} / \mathrm{m}^{3}$

coefficient of resistance to gas flow, $\mathrm{k} /$

Pa.s

mass of non-condensable gases, $\mathrm{Kg}$

monomer concentration, $\mathrm{kmol} / \mathrm{m}^{3}$

monomer mass in the condenser liquid

phase, $\mathrm{kg}$

reactor pressure, $\mathrm{Pa}$

condenser pressure, $\mathrm{Pa}$

fraction of the monomer vapor composed of non-condensable gases

reactor temperature, $\mathrm{K}$

temperature of the condensed monomer that returns to the reactor, $\mathrm{K}$ cooling fluid temperature, $\mathrm{K}$ global coefficient for heat exchange in the condenser, $\mathrm{j} / \mathrm{m}^{2}$.K.s

reactor volume

mass flowrate of monomer vapour that

leaves the reactor, $\mathrm{kg} / \mathrm{s}$

$\mathrm{W}_{\mathrm{vc}}$

$\mathrm{X}$

mass flowrate of condensed monomer vapour inside the condenser, $\mathrm{kg} / \mathrm{s}$ monomer conversion

\section{Greek symbols}

$\lambda_{0}, \lambda_{1}$

$\mu_{1}$

$\lambda_{\mathrm{v}}$

$\rho$

$\Delta \mathrm{HR}$

$\varepsilon$

$\chi$

moment of growing radicals zero order and first order

moment of dead polymer first order

monomer latent heat of vaporisation, $\mathrm{j} / \mathrm{kg}$

density, $\mathrm{kg} / \mathrm{m}^{3}$

monomer heat of reaction, $\mathrm{kj} / \mathrm{kmol}$

volume contraction factor

Flory-Huggins interaction parameter in the styrene-polystyrene system

\section{Subscripts}

C

f, o

$\mathrm{m}$

$\mathrm{p}$

r

$\mathrm{S}$

$\mathrm{V}$ refers to condenser

refers to feed or initial conditions

monomer

polymer

refers to coolant conditions

refers to output conditions

refers to vapor 


\section{INTRODUCTION}

Several characteristics of polymerization reactors lead to difficulties in the development of modeling and control of such systems (Toledo, 1992). Traditional cooling methods present low efficiency for these systems, whereas the utilization of a condenser connected to the reactor (auto refrigerated reactor) has proved to be an effective mechanism to remove heat from the reactor (Vasco de Toledo et al., 2000; Luyben, 1999; Toledo, 1992; Henderson and Cornejo, 1989 and Henderson, 1987).

The configuration studied in this work consists of a CSTR polymerization reactor connected to a semi-flooded horizontal condenser, as shown in Fig. 1. The temperature control in this system is carried out by a temperature controller connected to the reactor, operating in cascade with a level controller associated to the condenser. When non-condensable gases are not present in the system, a SISO control loop is sufficient for the system temperature control. In Fig. 1, TC is the temperature controller, $\mathrm{NC}$ the condenser level controller and $\mathrm{V}$ the valve that sends the condensate back to the reactor; the reactor temperature can be controlled by manipulating the condenser reflux flowrate, Fr (Toledo, 1992).

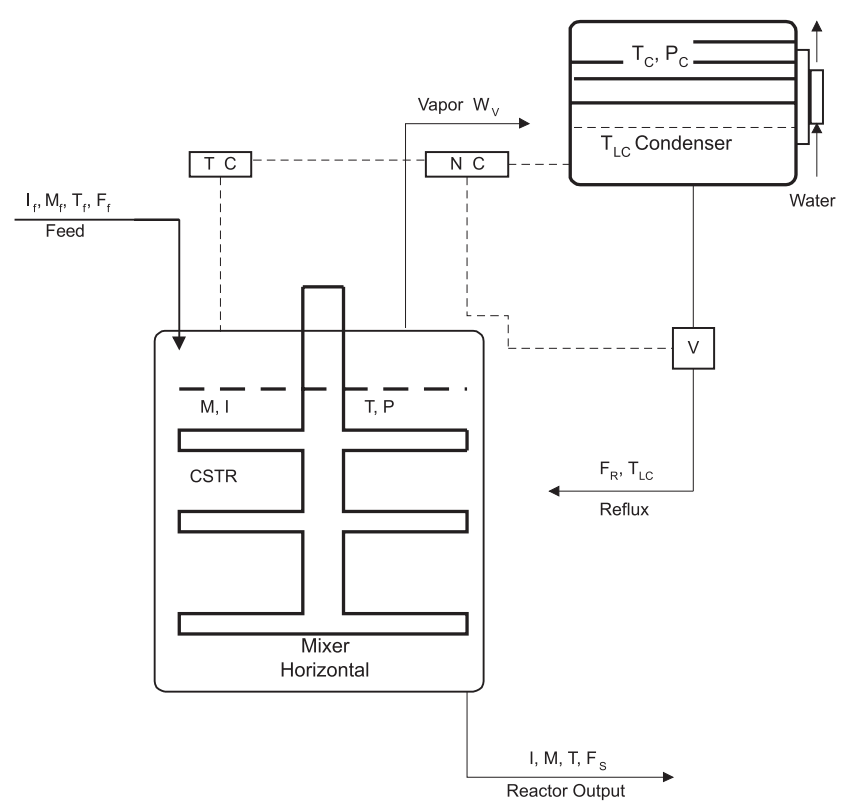

Figure 1. Scheme of a CSTR connected to a semi-flooded condenser.

The presence of non-condensable gases in the system is a concern, since they accumulate in the condenser, decreasing the heat exchange area and the level of condensed fluids, impairing the system cooling scheme. Furthermore, these gases alter the entire process dynamics, turning it into a purely transient system, and can lead the system to collapse after some operating time if the noncondensable gases are not purged from the condenser.

Therefore, in these cases, it is necessary to control the reactor temperature and, periodically, to purge the non-condensable gases in the condenser. This problem can be solved by controlling the reactor temperature manipulating the reflux flowrate of the condensed material, $\mathrm{Fr}$, and by controlling the purge of non-condensable gases to prevent the level of condensed fluid from reaching critical values.

The studied control algorithms were the classic PI, the long range predictive control QGPC ("Generalized Predictive Control" with restrictions using optimization routine, $\mathrm{SQP}$ ) and the adaptive predictive control STQGPC (QGPC coupled to the identification algorithm RLS).

\section{KINETIC MECHANISM OF REACTION}

The object of study, considering the objectives of this work, was the bulk polymerisation via styrene free radicals, because this is a well-known process with many studies published in the literature, besides its great industrial importance. The description of the reactions involved in the bulk polymerisation of styrene via free radicals consists of the following steps:

Initiation

$\mathrm{I} \square \mathrm{Ju}^{\mathrm{S}} \mathrm{O} 2 \mathrm{R}_{0}$

$\mathrm{R}_{0} \square \mathrm{M} \square$ Gै $^{\circ} \mathrm{R}_{1}$

Thermal initiation

$3 \mathrm{M} \square$ 解 $2 \mathrm{R}_{1}$

Propagation

$\mathrm{R}_{\mathrm{x}} \square \mathrm{M} \square \bigsqcup^{\mathrm{k}} \mathrm{O} \mathrm{R}_{\mathrm{x} \square 1}$

Chain transfer to the monomer

$\mathrm{R}_{\mathrm{x}} \square \mathrm{M} \square$ 訨o $\mathrm{P}_{\mathrm{x}} \square \mathrm{R}_{1}$

Termination by combination

$R_{x} \square R_{y} \square$ t. $0 P_{x \square y}$ 
where I and $\mathrm{M}$ are the initiator and the monomer respectively, $R_{x}$ is a growing macro-radical of chain length equals $x, P_{x}$ is a dead polymer of chain length $\mathrm{x}$ and $\mathrm{K}_{\mathrm{d}}, \mathrm{K}_{\mathrm{i}}, \mathrm{K}_{\mathrm{m}}, \mathrm{K}_{\mathrm{p}}, \mathrm{K}_{\mathrm{tm}}$ and $\mathrm{K}_{\mathrm{tc}}$ are the kinetic constants of the initiator decomposition, initiation, thermal initiation, propagation, chain transfer to the monomer and termination by combination, respectively.

Experimental results show that the polymerisation of styrene via free radicals presents autoacceleration (gel effect) of the polymerisation rate during the reaction. This phenomenon was considered by using the gel effect model of Hui and Hamielec (1972) and Husain and Hamielec (1978), which presents the following equations:

$$
\begin{aligned}
& \mathrm{K}_{\mathrm{tc}} \quad \mathrm{K}_{\mathrm{tco}} \exp \left(\square 2\left(\mathrm{~A}_{1} \mathrm{X} \square \mathrm{A}_{2} \mathrm{X}^{2} \square \mathrm{A}_{3} \mathrm{X}^{3}\right)\right) \\
& \mathrm{A}_{1} \quad 2.57 \square 5.05 \times 10^{\square 3} \mathrm{~T} \\
& \mathrm{~A}_{2} \quad 9.56 \square 1.76 \times 10^{\square 2} \mathrm{~T} \\
& \mathrm{~A}_{3} \quad \square 3.03 \square 7.85 \times 10^{\square 3} \mathrm{~T} \\
& \mathrm{~K}_{\mathrm{tm}} \quad \mathrm{K}_{\mathrm{tme}} \square \mathrm{K}_{\mathrm{p}} \mathrm{B}_{1} \mathrm{X}
\end{aligned}
$$

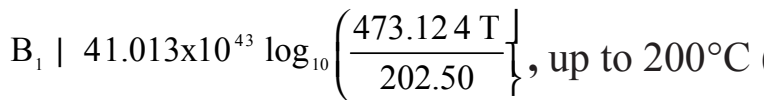

$$
\begin{aligned}
& \mathrm{B}_{1} \frac{0.01 \mathrm{E}_{1}}{1 \square 2 \mathrm{E}_{1}}
\end{aligned}
$$

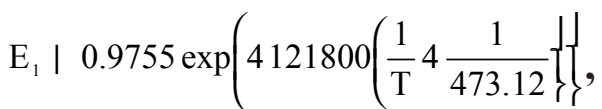

above $200^{\circ} \mathrm{C}$

The remaining kinetic constants $\left(\mathrm{K}_{\mathrm{d}}, \mathrm{K}_{\mathrm{i}}, \mathrm{K}_{\mathrm{m}}\right.$, $\mathrm{K}_{\mathrm{p}}, \mathrm{K}_{\mathrm{tmo}}$ and $\mathrm{K}_{\mathrm{tco}}$ ) are expressed by the classic Arrhenius equation (Farber and Ydstie, 1986; Hui and Hamielec, 1972; Husain and Hamielec, 1978).

It is convenient to mention that, as $\mathrm{x}$ (in the kinetic mechanism) can vary mathematically from 2 to $\infty$, the process description results in a model with an infinite number of differential equations. In order to reduce it, dead polymers and growing radicals distribution moment are introduced. The kth momentum of growing radicals is defined as:

$$
\left.\mathrm{O}_{\mathrm{K}}\right|_{x=1} ^{\mathrm{f}} \mathrm{x}^{\mathrm{k}} \mathrm{R}_{\mathrm{x}}
$$

And the kth momentum of dead polymers is:

$$
\left.P_{K}\right|_{x} ^{f} x^{K} P_{x}
$$

\section{DESCRIPTION OF THE PROCESS MODEL}

The mathematical modeling aims to represent the dynamic behavior of the system in a realistic way, to evaluate the cooling potential and the effect of non-condensable gases on the system behavior. The model takes into account the variation of the: (i) physical properties, (ii) reaction heat, and (iii) global coefficient of heat transfer, and uses the Flory-Huggins equation to describe the reactor pressure. In this work, the case study considered is the bulk polymerization via styrene free radicals, which incorporates the auto acceleration (gel effect) of the polymerization rate during the reaction. The simplifying hypotheses considered, as well as details regarding the solution of the model, can be found in Toledo (1992) and Vasco de Toledo et al. (2000).

\section{CSTR Reactor:}

$$
\begin{gathered}
\frac{d I}{d t} \quad \frac{F_{f}}{V} I_{f} \square \frac{F_{s}}{V} I \square K_{d} I \\
\frac{d M}{d t} \quad \frac{F_{f}}{V} M_{f} \square \frac{F_{s}}{V} M \square\left(K_{p} \square K_{t m}\right) M Q \\
\frac{d T}{d t} \quad \frac{F_{f}}{V} T_{f} \square \frac{F_{s}}{V} T \square \frac{\square^{\prime} H_{R} \llbracket \mid K_{p} \square K_{t m}\lfloor M Q}{U C_{p}} \\
\square \frac{F_{R}}{V} T_{l c} \square \frac{W_{v} \llbracket C_{P} T \square O_{v} \square}{U C_{\mathrm{P}} \mathrm{V}}
\end{gathered}
$$




$$
\begin{aligned}
& \frac{d F_{1}}{d t} \quad K_{t m} M Q \square K_{t c} Q Q \square \frac{F_{s}}{V} P_{1} \\
& X \frac{P_{1}}{P_{1} \square M},
\end{aligned}
$$

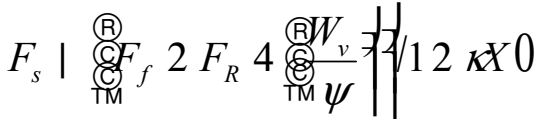

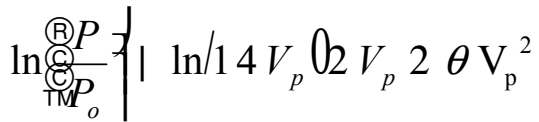

$\mathrm{P}_{\mathrm{o}} \quad \mathrm{f}_{1}(\mathrm{~T}), \mathrm{f}_{1}$ is a thermodynamic function

of the vapour pressure.

\section{Semi-Flooded Horizontal Condenser:}

$$
\begin{gathered}
W_{v} K\left(P \square P_{c}\right), W_{v c} \frac{U_{c} \mathrm{~A}_{c}\left[\mathrm{~T}_{c} \square T_{a}[\right.}{O_{v}} \\
\frac{d P_{c}}{d t} \frac{W_{v} \square W_{v c} @}{C_{T M} U_{v}}
\end{gathered}
$$

$T_{c} \quad f_{2}\left(P_{c}\right), f_{2}$ is an Antoine-type thermodynamic function.

$$
T_{l c} \quad \stackrel{\underline{\mathrm{a}}}{\underline{\ll}} T_{c} \square \frac{3}{4} T_{c} \square T_{a}{\stackrel{\rho}{L_{l}} / 4}_{4}
$$

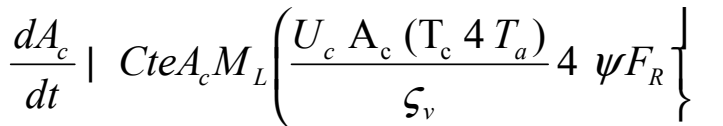

neglecting non-condensable gases

$$
\begin{array}{cc}
\frac{d M_{L}}{d t} \quad \frac{1}{C t e A_{c} M_{L}} \frac{d A_{c}}{d t} \\
\\
\mathrm{~F}_{\mathrm{R}} \quad \text { Cte } \mathrm{M}_{\mathrm{L}}, \text { (in open loop) } \\
\mathrm{F}_{\mathrm{R}} \quad \begin{array}{l}
\text { constant or provided by a control } \\
\text { algorithm (in closed loop) }
\end{array}
\end{array}
$$

\section{Physical Properties and Global Heat Transfer} Coefficient:

$$
\begin{array}{ll}
\text { CTE2 } & 24.2674 \square \frac{1800.73}{T} \square 0.00529 T \\
{ }^{\prime} H_{R} & 4186.8 \bigotimes C T E 2 \square
\end{array}
$$

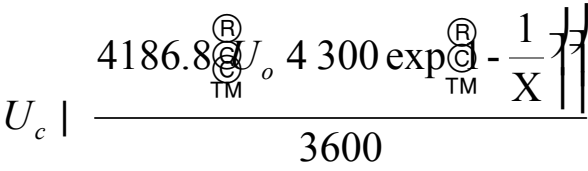

$$
\begin{aligned}
& \iota_{m} \quad 924.0 \square 0.981[T \square 273.15[ \\
& U_{p} \quad 1084.8 \square 0.605 \square \square 273.15 \square \\
& \frac{1}{U} \frac{X}{U_{p}} \square \frac{1 \square X \square}{U_{m}} \\
& \mathrm{Cp}_{\mathrm{m}} \quad 1.5491 \square 4.307 \times 10^{\square 03} \mathrm{~T} \\
& \mathrm{Cp}_{\mathrm{p}} \quad 1.2142 \square 4.040 \times 10^{\square 03} \mathrm{~T} \\
& \mathrm{Cp} \quad \mathrm{Cp}_{\mathrm{m}} \square \mathrm{X}\left[\mathrm{Cp}_{\mathrm{p}} \square \mathrm{Cp}_{\mathrm{m}}\right]
\end{aligned}
$$

\section{Effect of Non Condensable Gases:}

$$
\begin{gathered}
\text { CTE3 } \frac{U_{c} \mathrm{~A}_{\mathrm{c}}\left(\mathrm{T}_{\mathrm{c}} \square T_{a}\right)}{O_{v}} \square U F_{R} \square \frac{d m_{n c}}{d t} \\
\frac{d A_{c}}{d t} \quad \text { CteA } A_{c} M_{L} \text { XTE3@ } \\
\frac{\mathrm{dm}_{\mathrm{nc}}}{\mathrm{dt}} \quad \mathrm{W}_{\mathrm{v}} \text { perc }, 0<\text { perc }<1
\end{gathered}
$$

The parameter perc adjusts the flowrate of non-condensable gases entering the condenser, based on the vapor flowrate entering the condenser.

\section{RESULTS}

Figure 2 shows the stable and unstable operation points for this kind of reactor, when the generated and removed heat curves are plotted, without the presence of non-condensable gases.

The condenser reflux flowrate, Fr, was chosen as the manipulated variable to control the temperature of the reactor, therefore, it is important for the development of a control strategy to know the reactor temperature dynamic behavior in function of step perturbations in Fr. Figure 3 shows the temperature dynamic behavior for the unstable case and it can be observed that the system presents a high gain for this case. The reactor reaches a stable operation point of high conversion for negative disturbances in Fr, and it can be seen that positive perturbation leads to the reaction extinction. 


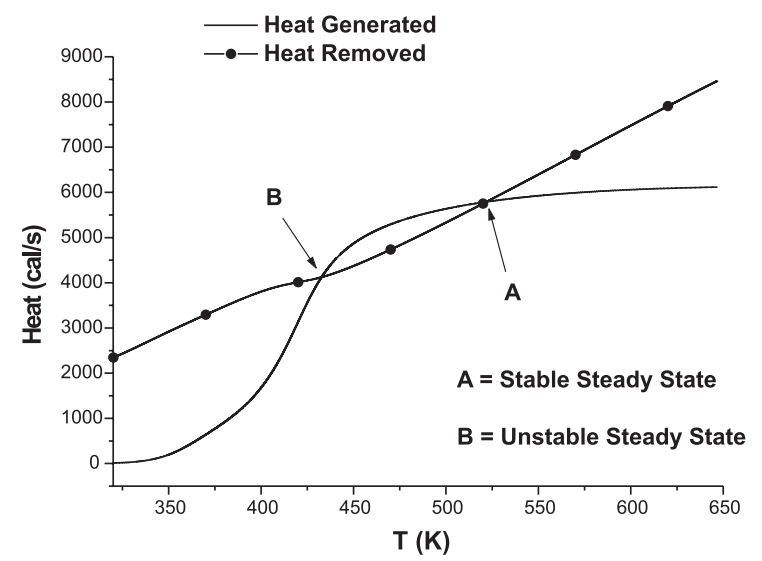

Figure 2. Curves of generated and removed heat.

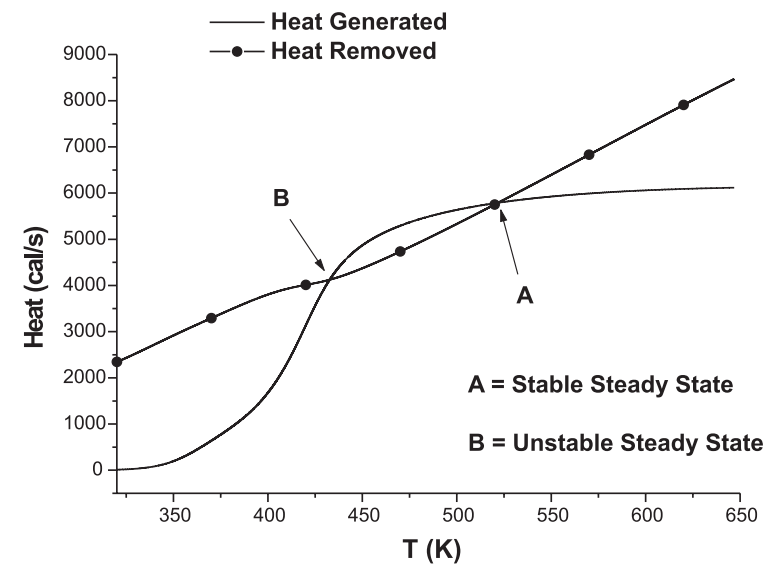

Figure 3. Curves of generated and removed heat.

Figures 4-6 show the effect of the presence of non-condensable gases in the system when there is no control strategy to compensate their influence, for both stable and unstable cases. As can be seen from these profiles, the system presents a transient characteristic, i.e., the non-condensable gases alter the entire process dynamics, turning it into a purely transient system: the condenser pressure and the reactor temperature increase. If these gases are not purged from the condenser, instead of reaching a steady state, the whole process will collapse. To overcome this problem and provide an efficient control strategy, this work proposes the purging of the gases when the level of liquid (or rather the mass of liquid) inside the condenser reaches a lower limit. The alternative of applying such control by monitoring the pressure has not shown to be a reliable strategy, because, in some situations, the dynamics involving this variable in the condenser presents dead time followed by an abrupt response.

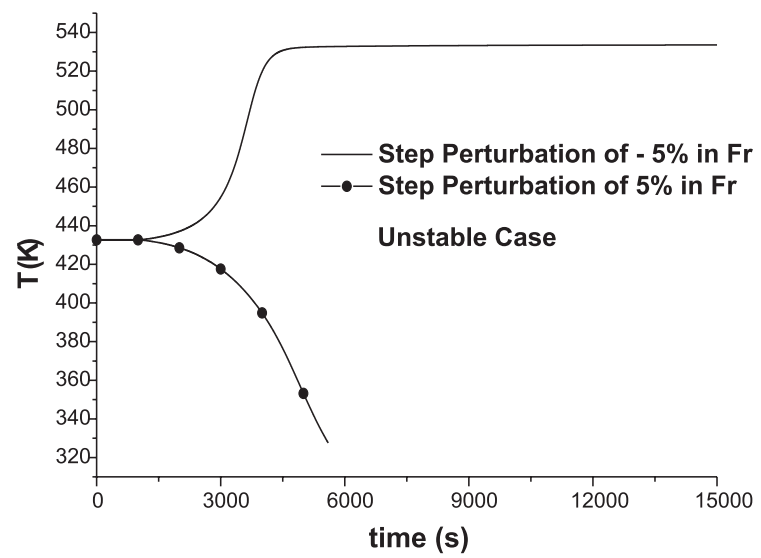

Figure 4. Dynamic behavior in system closed loop Unstable case.

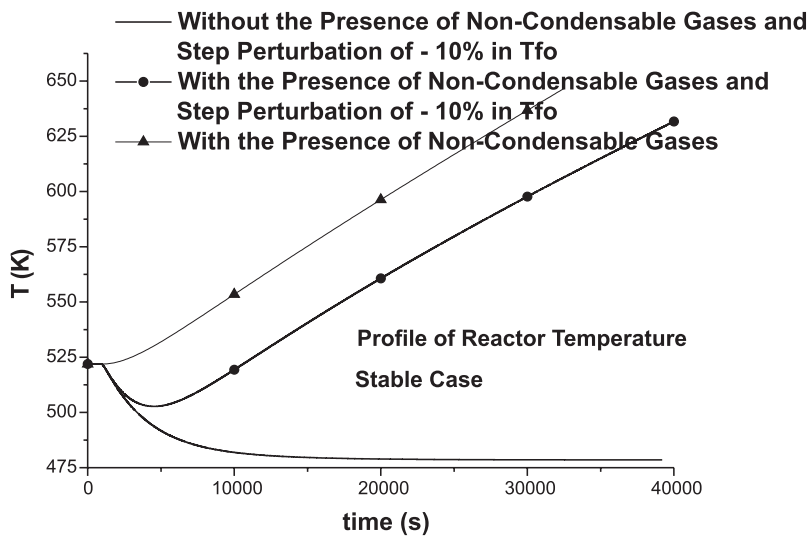

Figure 5. Temperature profile in the reactor Stable case.

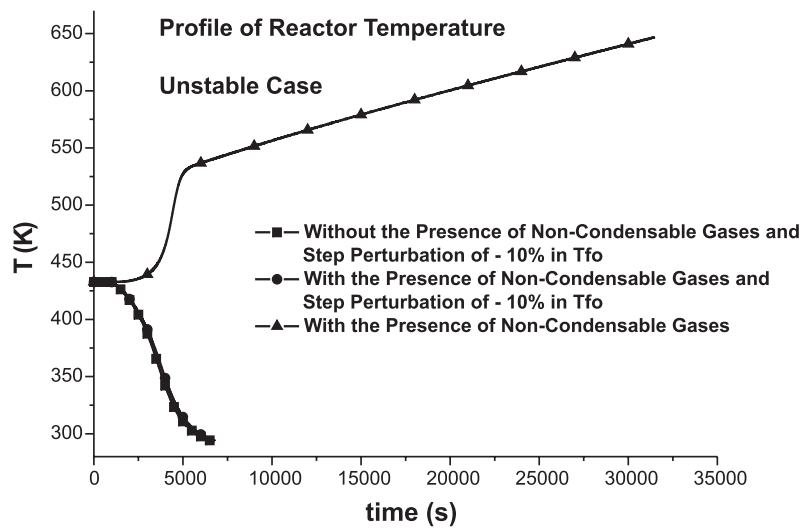

Figure 6. Temperature profile in the reactor Unstable case

The unstable point was chosen as the operating point of the reactor due to the greater difficulty in operating the systems under these conditions, allowing a better assessment of the performance of the different controllers studied here. Figures 7 (supervisory control), 8 and 9 (regulatory control) show that the influence of the non-condensable gases is counterbalanced and the system now reaches a steady-state in closed loop. 
Even operating in an unstable point, the control strategy performed well. Regarding the control algorithms studied, QGPC and STQGPC presented the best performances, showing that there is the need of using advanced control algorithms in order to operate the system safely and efficiently.

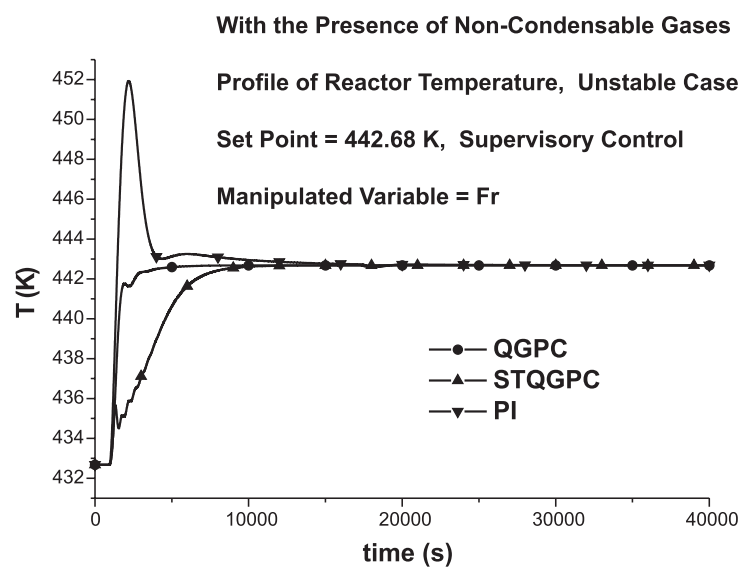

Figure 7. Supervisory control, manipulated variable Fr.

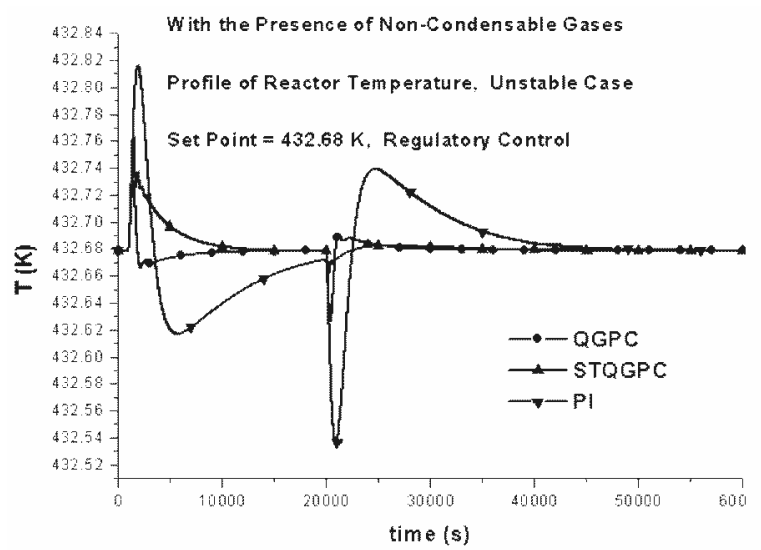

Figure 8. Regulatory control, manipulated variable Fr.

More details on the dynamic behavior of the system, in open and closed loop, without the presence of non-condensable gases and on the nomenclature can be found in Vasco de Toledo et al. (2000).

In all, Fig. 10 shows the manipulated variable behavior in the supervisory control case (Fig. 7) for the three controllers. It can be observed that the beginning of the simulation is more abrupt, becoming more steady and smooth in the later part of the simulation. Among the showed profiles, the QGPC presented the least variable dynamic profile to the manipulated variable, which is interesting in industrial applications.

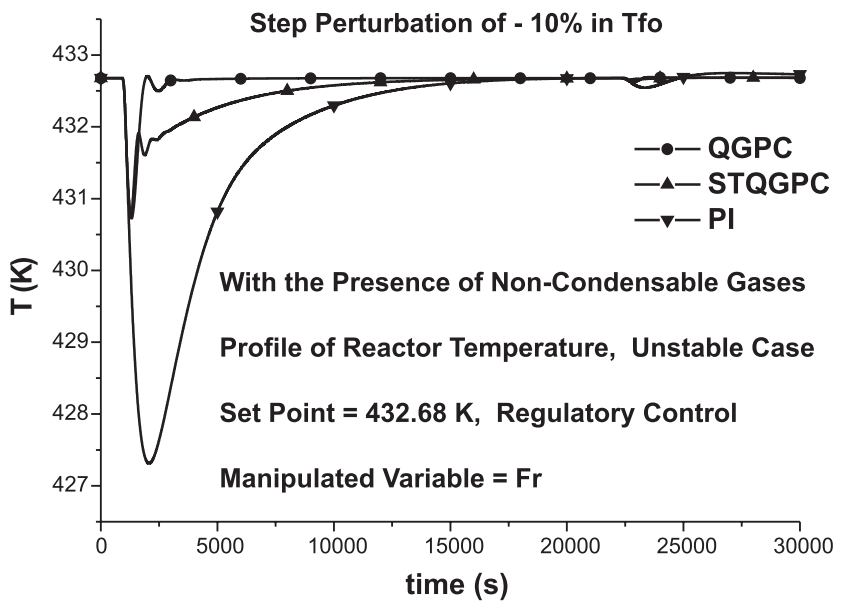

Figure 9. Regulatory control, manipulated variable Fr.

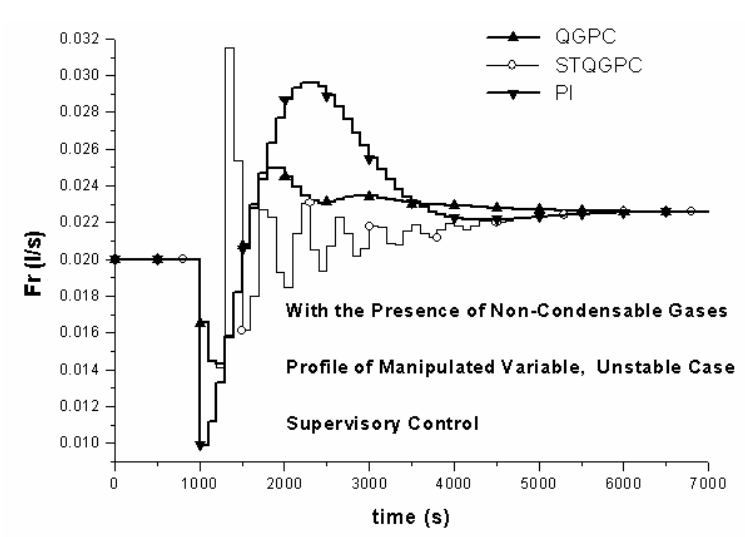

Figure 10. Supervisory control, profile of manipulated variable Fr.

\section{CONCLUDING REMARKS}

CSTR polymerization reactors present great heat exchange difficulties in practice; the cooling system described in this work is a good strategy to overcome the mentioned difficulties regarding this kind of reaction. It is convenient to mention that, to the best of our knowledge, the influence of non-condensable gases had not been taken into account before in the open literature. The presence of these gases works as a serious disturbance on the system, preventing it from ever reaching a steady state. The control strategy proposed in this work has efficiently addressed the problem, allowing the stable operation of the reactor under closed loop using advanced controllers, QGPC or STQGPC.

\section{ACKNOWLEDGEMENTS}

The authors are grateful to the Conselho Nacional de Desenvolvimento Cientifico e 
Tecnológico - CNPq and to the Fundação de Amparo à Pesquisa do Estado de São Paulo (FAPESP) for their financial support.

\section{REFERENCES}

Farber, J. N., Ydstie, B. E., 1986, Adaptive compensation for large disturbances in a continuous polymerization reactor, Ind. Eng. Chem. Fundam., Vol. 25, pp. 350-356.

Henderson, L. S., 1987, Stability Analysis of Polymerization in Continuous, Stirred-Tank Reactors, Chemical Engineering Progress, pp. 42-50.

Henderson, L. S., Cornejo, R. A., 1989, Temperature control of continuous, bulk styrene polymerization reactors and the influence of viscosity: An analytical study, Ind. Chem. Res., Vol. 28, pp. 1644-1653.

Hui, A. W., Hamielec, A. E., 1972, Thermal polymerisation of styrene at high conversions and temperatures. An experimental study, Journal of Applied Polymer Science, Vol. 16, pp. 749-769.

Husain, A., Hamielec, A. E., 1978, Thermal polymerisation of styrene, Journal of Applied Polymer Science, Vol. 22, 1207-1223.

Luyben, W. L., 1999, Temperature control of autorefrigerated reactors, Journal of Process Control, pp. 301-312.

Toledo, E. C. V., 1992, Modelling and control of a CSTR polymerization reactor connected to a semi-flooded horizontal condenser, MSc. Dissertation, COPPE/UFRJ, Rio de Janeiro (in Portuguese).

Vasco de Toledo, E. C., Martini, R. F., Maciel Filho, R., 2000, Development of high performance operational strategies for polymerization reactor, Computers \& Chemical Engineering., Vol. 24, No. 2-7, pp. 481-486. 